\title{
Invasive head and neck cutaneous squamous cell carcinoma: clinical and histopathological characteristics, frequency of local recurrence and metastasis*
}

\author{
Luiza Vasconcelos ${ }^{1}$ \\ Hélio Amante Miot ${ }^{1}$ \\ Luciana Patricia Fernandes Abbade ${ }^{1}$
}

\author{
Juliana Carneiro Melo ${ }^{1}$ \\ Mariângela Esther Alencar Marques ${ }^{1}$
}

DOI: http://dx.doi.org/10.1590/abd1806-4841.20142810

\begin{abstract}
BACKGROUND: squamous cell carcinoma is the second most common type of skin malignancy and may evolve to regional lymph node and distant metastases.

OвJестіvE: The objective of this study was to evaluate patients with head and neck cutaneous squamous cell carcinoma to identify its clinical and histopathological characteristics, as well as the frequency of local recurrence and metastasis.

METHODS: A retrospective cohort of patients with head and neck cutaneous squamous cell carcinoma. Inclusion criteria: histopathological confirmation, follow-up for longer than one year after diagnosis. Exclusion criteria: immunosuppression; lip and oral cavity squamous cell carcinoma; and non-surgical resection of the lesion. We evaluated demographic, clinical and anatomopathologic findings and explored their associations.

RESULTS: Sixty-one patients with 79 tumors and followed by $4.8 \pm 3.0$ years were selected. The average age was 67.1 years, and $63 \%$ of tumors had up to two centimeters. Seven tumors $(8.9 \%)$ recurred and two of them had positive margins. Recurrence was associated with higher Broders' grade $(\mathrm{p}<0.01)$. Two patients $(3.3 \%)$ had regional lymph node metastases. There were no distant metastases. Seventy tumors were considered to be usual tumors $(89.7 \%)$, and $68(87.2 \%)$ were classified as Broders' grade 1 and 2 . Additionally, $64.1 \%$ of tumors had a depth of invasion below four millimeters. Thirteen tumors (16.7\%) had positive histological margins.

CONCLUSIONS: Most patients had good prognosis in the first year of follow-up, confirming that head and neck cutaneous squamous cell carcinoma has a better prognosis than squamous cell carcinoma of other regions such as mucosa, oral cavity, and internal organs.
\end{abstract}

Keywords: Carcinoma, squamous cell; Lymphatic metastasis; Neoplasm recurrence, local; Pathology; Recurrence

\section{INTRODUCTION}

Squamous cell carcinoma (SCC) is a malignant keratinocytic neoplasm ${ }^{1}$ that represents the second most common skin cancer. It has an invasive nature and may evolve to metastases to regional lymph nodes and distant organs. ${ }^{2}$

SCC accounts for nearly $20 \%$ of epithelial neoplasms and predominates in Caucasians, especially in those living in tropical regions, due to chronic sun irradiation, which is an important risk factor for the disease. ${ }^{3}$

It is more common in males and individuals older than 50 years, because of the cumulative dose effect of ultraviolet solar radiation on skin and also because of smoking, a significant risk factor for lower lip SCC. Chemical products (such as arsenic and polycyclic hydrocarbons), human papilloma virus infections, immunosuppression, scars, and other chronic ulcerated dermatoses are other less frequent risk factors for the development of cutaneous SCC. ${ }^{3,4}$

This neoplasm can be totally cured, depending on tumor staging and individual characteristics. When the neoplasm cannot be cured, it can progress to metastasis, especially to regional lymph nodes, on average one or two years after diagnosis. ${ }^{5-7}$ Since photoexposed areas, especially head and neck, are the most affected by SCC, metastasis usually involves the lymph nodes located in these regions.

Received on 22.05.2013.

Approved by the Advisory Board and accepted for publication on 22.07.2013.

* Work conducted at the Department of Dermatology and Radiotherapy of School of Medicine Botucatu- Universidade Estadual Paulista "Júlio de Mesquita Filho" (Unesp) - Botucatu (SP), Brazil.

Financial support: None.

Conflict of interests: None

Universidade Estadual Paulista "Júlio de Mesquita Filho" (Unesp) - Botucatu (SP), Brazil. 
The incidence of patients with cutaneous SCC who develop lymph node metastasis is low, nearly 2 to $3 \%$. This is the case for previously untreated immunocompetent patients with small $(<2 \mathrm{~cm})$ and shallow $(<4 \mathrm{~mm})$ lesions, who are considered low-risk patients. $^{8}$

High-risk patients are defined as those whose likelihood of developing metastasis to head and neck lymph nodes is greater than $5 \%$, based on unfavorable factors related to the lesion and the patient. ${ }^{8,9}$

Therefore, the prognosis of cutaneous SCC depends mainly on clinical staging, the site affected by the tumor, lymph node involvement, and presence of distant metastasis. ${ }^{10}$

The aim of this study was to evaluate patients with head and neck cutaneous SCC on oncologic follow-up with the purpose of identifying their clinical and histopathological characteristics, as well as the frequency of local recurrences and metastases. The identification of factors that are possibly related to SCC prognosis may be useful for the development of better treatment and prevention strategies.

\section{METHODS}

This was a retrospective cross-sectional study including patients diagnosed with invasive head and neck SCC confirmed by anatomic pathology tests between 1999 and 2003. This research complied with the principles set forth in the Declaration of Helsinki and was approved by the local research ethics committee.

\section{- Inclusion criteria}

- Diagnosis of invasive primary head and neck SCC confirmed by anatomic pathology tests.

- Outpatient follow-up of at least one year after anatomic pathology diagnosis.

\section{- Exclusion criteria}

- Immunosuppressed patients

- Patients with lip and oral SCC (whether previous or current)

- Patients who had previously undergone radiation therapy

- Patients who underwent treatments other than surgical resection of the lesion.

SCC was considered primary or de novo when it occurred for the first time on a given site of the skin. Local recurrence occurred when the tumor developed on the same site of a tumor resected in a previous surgery, whether its margin was classified as positive or negative on anatomopathological exam.

Locoregional metastasis occurred when aspiration cytology and/or anatomopathological exam on surgical specimens or biopsies of lymph nodes from submandibular, cervical and/or parotid regions showed atypical squamous cells. Distant metastasis occurred when there were atypical cells in organs and tissues and/or lymph nodes located at sites other than cervical and submandibular regions.

The study analyzed demographic variables (gender, and age at tumor onset) and clinical variables (number, location and size of lesions; duration of lesions; presence of clinically abnormal lymph nodes; presence of masses on the parotid region; presence of recurrence, locoregional metastasis, and distant metastasis; time of follow-up; and personal history of smoking, alcoholism, other malignant neoplasms, immunosuppression, albinism, xeroderma pigmentosum).

Anatomopathological variables were obtained after histological slides were reviewed by a physician specialized in dermatology and pathology. Because it was a blinded study, the examiner was unaware of the evolution of the cases analyzed. The following histopathological criteria were considered:

- Macroscopy: size of the lesion in centimeters and of lateral margins in millimeters;

- Histological type: usual, achantolytic, fusiform cells, verrucous, SCC in Bowen's disease, desmoplastic, adenosquamous (production of mucin)

- Presence or absence of ulceration;

- Degree of differentiation (Broders' grade): grade $1(<25 \%$ of undifferentiated cells), grade 2 ( $325 \%$ and $<50 \%)$, grade $3\left({ }^{3} 50 \%\right.$ and $\left.<75 \%\right)$, and grade $4\left({ }^{3} 75 \%\right)$;

- Tumor thickness in millimeters (Breslow thickness);

- Occurrence of perineural invasion;

- Occurrence of perivascular invasion;

- Histological margins: free of tumor, positive lateral margins, positive deep margins, positive lateral and deep margins, margins with in situ SCC, margins with actinic keratosis, and tiny margins (smaller than $1 \mathrm{~mm})$;

- Smallest deep margin free of tumor (in millimeters);

- Changes in adjacent skin: no changes, actinic keratosis, and solar lentigo;

- Inflammatory infiltrate: mild, moderate, and severe.

Categorical variables were represented as percentages and quantitative variables as mean and standard deviation or median and interquartile range (percentile 25-percentile 75) if data normality was not checked using the Lilliefors test.

Database was created and analyzed using the Statistical Package for Social Sciences software (SPPS Inc., Chicago, USA), version 20.0. Percentages were compared by the chi-square, chi-square for linear trend, 
and Fisher's exact tests. Student's t and Mann-Whitney tests were used to compare quantitative variables. The correlation between quantitative variables was investigated using Pearson's or Spearman's coefficients, if applicable. Significance level was set at 5\%.

\section{RESULTS}

We selected 61 patients with 100 tumors of head and neck cutaneous SCC. Twenty-one tumors were excluded from the study because they did not meet inclusion criteria and one tumor was excluded because histological material was not available. Thus, 79 tumors underwent clinical analysis and 78 tumors were analyzed by means of anatomopathological exam.

In terms of gender, 35 of the 61 patients were men $(57.4 \%)$. The mean age at tumor onset was $67.1 \pm 13.3$ years. Thirteen patients $(21.3 \%)$ had a history of smoking and four patients $(6.5 \%)$ had a history of alcohol abuse.

Forty patients $(65.6 \%)$ had only one head and neck cutaneous SCC, 14 patients $(22.9 \%)$ had two carcinomas, and two patients (3.3\%) had more than three lesions. Those patients who had one tumor had a chance of $22.2 \%$ of having a second tumor.

The median duration of the tumors was 12 (636) months. The mean tumor size was $1.7 \pm 0.9 \mathrm{~cm}$, and $63.4 \%$ of the tumors had up to $3 \mathrm{~cm}$ in diameter (T1).

Regarding the site of head and neck cutaneous SCC, over $75 \%$ of cases were detected in the mandibular, maxillary, frontal, nasal, and ear regions (Table 1).

Patients were followed up for a median period of 5 (2-7) years. Seven tumors recurred $(8.9 \%)$ and $85.8 \%$ of these recurrences happened within the first three years of follow-up (Table 2). Of the seven recurrent tumors, two had positive surgical margins on the anatomic pathology test and one patient with relapse showed regional metastasis. There was no association between site and tumor recurrence (Table 1).

Seventy tumors were classified as usual tumors $(89.7 \%)$ and eight were considered to be acantholytic (10.3\%). Fifty-two tumors were ulcerated (66.7\%). In terms of histological differentiation (Broders), tumors with higher grades were more likely to relapse (Table 1).

Two patients had metastases to regional lymph nodes (3.3\%); one with a lesion in the mandibular/maxillary region and the other one in the neck. In one of these patients, metastasis occurred in the first year of follow-up and the other patient had metastasis in the fourth year of follow-up. No patient had metastases in the parotid region or distant metastases.

The median thickness of the tumors was $3(2-4)$ $\mathrm{mm}$. Fifty tumors $(64.1 \%)$ were between 1 - and $4-\mathrm{mm}$ thick (Table 2). There was no correlation between Breslow thickness and the duration of the tumors ( $\mathrm{rs}=-$ $0.1 ; \mathrm{p}=0.53)$, or association with recurrence $(\mathrm{p}=0.65)$.
Most tumors showed no perivascular infiltrate or perineural invasion. There was no association of perineural invasion and perivascular infiltrate with tumor recurrence (Table 1). Fifty-eight tumors $(74.4 \%)$ had free histological margins and 13 tumors (16.7\%) had positive surgical margins (Table 3 ).

Fifty-four tumors $(69.3 \%)$ had 1- to 4-mm free deep margins, and 14 tumors $(17.9 \%)$ had margins larger than $4 \mathrm{~mm}$. The median of free deep margins was $2.0(1-4) \mathrm{mm}$ (Table 3). As to the smallest free lateral margin, the size of 53 tumors $(67.9 \%)$ was between 1 and $4 \mathrm{~mm}$, and the size of 11 tumors $(14.1 \%)$ was larger than $4 \mathrm{~mm}$. The median of free lateral margins was 2.0 (1-4) mm (Table 3).

Regarding the inflammatory infiltrate, there was no association between intensity and Broders' grade $(\mathrm{p}=0.41)$ or relapse (Table 1$)$.

All tumors with positive surgical margins were surgically re-approached. There was no association with the involvement of the surgical margin and recurrence (Table 1).

\section{DISCUSSION}

Because its main risk factor is exposure to ultraviolet rays from the sun, cutaneous SCC affects the head and neck region more often. Although cutaneous SCC is a common malignant neoplasm in Brazil, there are few national studies about the factors that have an influence on its prognosis. ${ }^{11}$

We found a slight male predominance and mean age for tumor onset was 67 years, which is in agreement with other studies. ${ }^{12,13}$ Most patients had only one tumor in the head and neck region. A large proportion of patients developed other skin tumors during the follow-up period. It is worth mentioning that immunosuppressed patients, such as transplant recipients, were excluded. The development of more than one tumor in the head and neck may be related to the cumulative dose effect of solar ultraviolet radiation associated with genetic predisposition. A prospective study of 300 patients with skin cancer showed that two-thirds of the patients developed a new skin tumor within 10 years. ${ }^{14}$ It has been demonstrated that a history of skin tumors and male gender are risk factors for other neoplasms, such as SCC and melanomas. ${ }^{14,15}$.

The size of the SCC upon diagnosis is important because it is related to patient's prognosis. The increase in tumor size is associated with increased risk of recurrence and regional lymph node metastases. ${ }^{16}$ As the tumor size was equal to or smaller than $2 \mathrm{~cm}$ in diameter, most patients in this study was classified as stage T1 based on the TNM classification

However, size is only a prognostic criterion. Other anatomic pathologic criteria of the tumor should be considered, such as depth of invasion, his- 
TABLE 1: Frequency and presence of recurrence in cutaneous head and neck SCC according to topography (N=79), Broders' grade, inflammatory infiltrate, perineural invasion, and positive margins $(\mathrm{N}=78)$

\begin{tabular}{|c|c|c|c|c|c|}
\hline \multirow[t]{2}{*}{ Location } & \multicolumn{2}{|c|}{ Frequency } & \multicolumn{2}{|c|}{ Recurrence } & \multirow[t]{2}{*}{$\mathrm{p}$} \\
\hline & $\mathbf{N}$ & $(\%)$ & $\mathbf{N}$ & $(\%)$ & \\
\hline Neck & 3 & (4) & 1 & (33) & 0.88 \\
\hline Ear & 5 & (6) & - & $(-)$ & \\
\hline Lip* and chin & 5 & (6) & - & $(-)$ & \\
\hline Mandibular and maxillary & 20 & (25) & 3 & (15) & \\
\hline Frontal & 18 & (23) & 1 & (6) & \\
\hline Pre- and retroauricular & 7 & (9) & - & $(-)$ & \\
\hline Scalp & 4 & (5) & 1 & (25) & \\
\hline Nasal & 16 & (20) & 1 & (6) & \\
\hline Unspecified & 1 & (1) & - & $(-)$ & \\
\hline \multicolumn{6}{|l|}{ Broders' grade } \\
\hline I & 41 & (53) & 2 & (5) & $<0.01$ \\
\hline II & 27 & (35) & 2 & (7) & \\
\hline III & 3 & (4) & - & $(-)$ & \\
\hline IV & 7 & (9) & 3 & (43) & \\
\hline \multicolumn{6}{|l|}{ Inflammatory infiltrate } \\
\hline Mild & 34 & (43) & 1 & (3) & 0.22 \\
\hline Moderate & 26 & (33) & 4 & (15) & \\
\hline Severe & 18 & (24) & 2 & (11) & \\
\hline \multicolumn{6}{|l|}{ Surgical margins } \\
\hline Free of tumor & 67 & (86) & 5 & (7) & 0.25 \\
\hline Positive & 11 & (14) & 2 & (18) & \\
\hline \multicolumn{6}{|l|}{ Perivascular infiltrate } \\
\hline No & 71 & (91) & 6 & (8) & 0.48 \\
\hline Yes & 7 & (9) & 1 & (14) & \\
\hline \multicolumn{6}{|l|}{ Perineural infiltrate } \\
\hline No & 72 & (94) & 6 & (8) & 0.38 \\
\hline Yes & 5 & (6) & 1 & (20) & \\
\hline
\end{tabular}

* not included labial mucosa

tological differentiation grade, presence of perineural and lymphovascular invasion, because many patients in stages T1 and T2 may develop regional and distal metastases. $^{3,17}$

Most head and neck cutaneous SCCs were located in the mandibular, maxillary, frontal, nasal, auricular, pre- and retroauricular regions. Lesions in the ear and in its surrounding region are related to higher incidence of regional metastasis. ${ }^{18,19}$ There are studies suggesting that elective regional lymphadenectomy should be performed in patients with high-risk SCC in this region. ${ }^{19,20}$ In the present study, there were 12 lesions in the ear and its surrounding region, and there was no recurrence and related metastases. This may be due to the fact that we found only seven recurrences and two metastases, which hindered the statistical analysis.

During the follow-up period, $8.9 \%$ of tumors had local recurrence. Half of the recurrences occurred within the first year after tumor resection, and the other half occurred up to three years after resection. Recurrence is also associated with regional metastasis. About one third of the patients with recurrence showed positive histological margins. Patients with incomplete resection are at increased risk for recurrence and subsequent regional metastasis. ${ }^{16,21}$ Veness et al. found $15 \%$ of recurrence in patients who had 
TABLE 2: Time for recurrence of the seven recurrent head and neck SCCs, and thickness (level of invasion) of 78 SCCs

\begin{tabular}{cll}
\hline Time for recurrence & $\mathbf{N}$ & $\mathbf{\%}$ \\
\hline Less than 1 year & 3 & 42.9 \\
Between 1 and 2 years & 2 & 28.6 \\
Between 2 and 3 years & 1 & 14.3 \\
Between 3 and 4 years & - & - \\
Between 4 and 5 years & 1 & 14.3 \\
More than 5 years & - & - \\
Tumor thickness (mm) & & \\
$<1$ & 5 & 6.4 \\
1-2 & 15 & 19.2 \\
$2-3$ & 17 & 21.8 \\
$3-4$ & 18 & 23.1 \\
$4-5$ & 6 & 7.7 \\
5-6 & 7 & 9.0 \\
$6-7$ & - & - \\
$>$ or $=7$ & 10 & 12.8 \\
\hline
\end{tabular}

TABLE 3: Presence of tumor on histological margins and smallest histological margins free of tumor in the 78 SCCs

\begin{tabular}{lll}
\hline Margins & $\mathbf{N}$ & $\%$ \\
\hline Free of tumor & 58 & 74.4 \\
Positive lateral margins & 6 & 7.8 \\
Positive deep margins & 2 & 2.5 \\
Positive lateral and deep margins & 5 & 6.4 \\
Actinic keratosis & 4 & 5.1 \\
Tiny margins & 3 & 3.8 \\
Smallest free deep margin $(\mathbf{m m})$ & & \\
$<1$ & 5 & 6.4 \\
$1-2$ & 30 & 38.5 \\
$2-3$ & 12 & 15.4 \\
$3-4$ & 12 & 15.4 \\
$4-5$ & 9 & 11.5 \\
$5-6$ & 2 & 2.6 \\
$>6$ & 3 & 3.8 \\
Positive & 5 & 6.4 \\
Smallest free lateral margin $(\mathbf{m m})$ & & \\
$<1$ & 6 & 7.7 \\
$1-2$ & 15 & 19.2 \\
$2-3$ & 22 & 28.2 \\
$3-4$ & 16 & 20.5 \\
$4-5$ & 7 & 9.0 \\
$5-6$ & 1 & 1.3 \\
$>6$ & 3 & 3.8 \\
Positive & 8 & 10.3 \\
\hline
\end{tabular}

metastatic disease. ${ }^{3}$ Another study found that $50 \%$ of SCC lesions with positive margins recurred with consequent increased risk of developing metastases. ${ }^{22}$

In terms of histological findings, most head and neck SCCs were considered to be usual tumors and were ulcerated. Most tumors showed invasion level between 1 and $4 \mathrm{~mm}$, which probably contributes to the good prognosis of most patients. It is worth mentioning that 17 tumors had more than $4 \mathrm{~mm}$ of invasion, however there was no correlation between recurrence and Breslow's classification. A depth of invasion greater than $4 \mathrm{~mm}$ is an important predictor for regional lymph node metastases. ${ }^{3,23}$ A study of head and neck SCC showed that only $17 \%$ of patients had metastases when their lesions were smaller than 4-mm deep, compared with $83 \%$ of patients with metastases when their lesions were larger than $4 \mathrm{~mm}$ in depth. ${ }^{6}$

In addition, most cases had well-differentiated tumors, which reinforced the good prognosis of most patients. Poorly differentiated SCCs are associated with higher incidence of regional metastases. ${ }^{23}$ The incidence of undifferentiated lesions in a series of patients with SCC was significantly higher in patients who developed metastases. ${ }^{16}$ In our study, tumors with higher Broder's grades were more likely to recur. Although perineural and perivascular invasion is a risk factor for recurrences and metastases, these occurred in a small number of tumors (6.4 and 9.0\% respectively) in our study, and there was no correlation with recurrence. ${ }^{23,24}$ These findings may be explained by the low frequency of recurrences and metastases we found, with the need for a larger sample. Other studies showed that perineural invasion occurred in approximately $5-10 \%$ of tumors, and this was usually an incidental finding related to lymph node metastasis. ${ }^{16,25}$

The histological margins of most tumors were free of neoplasm, but the measures of the smallest free margins are a finding of interest. The smallest deep and lateral margins free of tumors measured less than $4 \mathrm{~mm}$ in $75.7 \%$ and $75.9 \%$ of tumors, respectively. The deep and lateral margins were positive in $6.4 \%$ and $10.3 \%$ of tumors, respectively. Therefore, the deep and lateral margins of approximately $80 \%$ to $86 \%$ of tumors respectively showed inadequate margins from the safety standpoint, since the recommended macroscopic margin is $4 \mathrm{~mm}$. It has been demonstrated that there is contraction of the elastic fibers after surgical resection, causing a reduction of the microscopic margin in relation to the macroscopic margin, which may explain in part our results. Another factor to be considered is that the free macroscopic margins may include undetectable microscopic lesions. Despite this percentage of tumors with microscopic margins smaller than $4 \mathrm{~mm}$, most cases had a good prognosis because only seven tumors recurred. 
There is no consensus regarding the definition of acceptable surgical margins for SCC. In a series of patients who had their tumors resected with minimal margins of $3 \mathrm{~mm}$, only $3 \%$ had recurrence with a mean follow-up period of 5.1 years. ${ }^{26}$ In another study, in the SCCs smaller than $2 \mathrm{~cm}$ that were resected with surgical margins of $4 \mathrm{~mm}$ and in the SCCs larger than $2 \mathrm{~cm}$ that were resected with surgical margins of $6 \mathrm{~mm}, 95 \%$ of tumors had microscopic margins free of cancer. ${ }^{27}$ The patients with inadequately resected SCCs should undergo very close follow-up, since there is increased risk of recurrence and metastasis. New surgery combined with radiotherapy intervention should be considered in these cases. ${ }^{28}$

Our results confirm that skin SCC has a different behavior from SCCs in other regions, such as SCCs in the mucosa, oral cavity, and internal organs (lungs), where the incidence of metastases is higher. Only two patients $(3.3 \%)$ had metastases in regional lymph nodes. This result is similar to the findings of other studies where the frequency of metastatic cutaneous SCC in regional lymph nodes is low, i.e., less than $5 \%$ of cases. ${ }^{9,29}$ The following are considered risk factors for regional and distant metastases: lesions larger than $2 \mathrm{~cm}$, lesion depth greater than $4 \mathrm{~mm}$, incomplete or inadequate margin resection, recurrent tumors, undifferentiated tumors, lymphovascular and perineural invasion, location near the parotid gland (auricular, temporal, frontal, and anterior scalp regions), and immunosuppression. . $8,9,28,30^{\text {Often, }}$ patients at high risk for metastases have more than one risk factor.
Although some patients have high risk for regional lymph node metastases, prophylactic lymphadenectomy is still controversial in these patients due to lack of evidence in the literature. In its guideline for management of patients with cutaneous SCC, the British Association of Dermatologists does not recommend prophylactic lymphadenectomy because of insufficient evidence. ${ }^{31}$ Adjuvant radiotherapy is an alternative to be considered in high-risk patients, since recent evidence has shown that it improves locoregional control and survival of patients with cutaneous SCCA..$^{9,28}$

In the present study, the retrospective design and the patients' old age prevented the determination of skin type (Fitzpatrick classification), a major epidemiological risk factor for SCC. This did not prevent the determination of clinical and histopathological characterization and the proposed analysis of recurrences and metastases.

Oncological follow-up of patients with skin SCC is important because of the risk of recurrence and spread, as well as determination of risky skin types, recommendations for sun protection, early treatment of actinic keratoses, and field cancerization. ${ }^{32-34}$

\section{CONCLUSION}

Most patients had good prognosis, confirming that head and neck skin SCC has a better prognosis than in other regions, such as mucosa, oral cavity, and internal organs (e.g., lungs). $\square$ 


\section{REFERENCES}

1. Schwartz RA. Premalignant keratinocytic neoplasms. J Am Acad Dermatol. 1996;35:223-42

2. Weinberg AS, Ogle CA, Shim EK. Metastatic cutaneous squamous cell carcinoma: an update. Dermatol Surg. 2007:33:885-99.

3. Veness MJ, Palme CE, Morgan GJ. High-risk cutaneous squamous cell carcinoma of the head and neck: results from 266 treated patients with metastatic lymph node disease. Cancer. 2006:106:2389-96.

4. Sampaio SAP, Rivitti EA. Tumores Epiteliais Malignos. In: Sampaio SAP, Rivitti EA, editores. Dermatologia. São Paulo: Artes Médicas Ltda; 2007. p. 1163-9.

5. Dinehart SM, Pollack SV. Metastases from squamous cell carcinoma of the skin and lip. An analysis of twenty-seven cases. J Am Acad Dermatol. 1989;21:241-8.

6. Kraus DH, Carew JF, Harrison LB. Regional lymph node metastasis from cutaneous squamous cell carcinoma. Arch Otolaryngol Head Neck Surg. 1998;124:582-7.

7. Tavin E, Persky M. Metastatic cutaneous squamous cell carcinoma of the head and neck region. Laryngoscope. 1996;106:156-8.

8. Sittart JAS. Câncer de Pele - Carcinoma Espinocelular. In: Lopes AC, editor. Tratado de Clínica Médica. São Paulo: Roca; 2006. p. 4887-8.

9. Veness MJ, Porceddu S, Palme CE, Morgan GJ. Cutaneous head and neck squamous cell carcinoma metastatic to parotid and cervical lymph nodes. Head Neck. 2007;29:621-31.

10. Beltrami CA, Desinan L, Rubini C. Prognostic factors in squamous cell carcinoma of the oral cavity. A retrospective study of 80 cases. Pathol Res Pract. 1992;188:510-6.

11. Nunes DH, Back L, Vieira e Silva R, Medeiros Vde S. Incidence of squamous cell carcinoma of the skin in the city of Tubarao (SC)--Brazil in the years 2000, 2003, and 2006. An Bras Dermatol. 2009;84:482-8.

12. Staples M, Marks R, Giles G. Trends in the incidence of non-melanocytic skin cancer (NMSC) treated in Australia 1985-1995: are primary prevention programs starting to have an effect? Int J Cancer. 1998;78:144-8.

13. Stang A, Stegmaier C, Jockel KH. Visual inspection of age-specific incidence rates: don't forget the scaling! Arch Dermatol. 2004;140:361-2.

14. Czarnecki D, Sutton T, Czarnecki C, Culjak G. A 10-year prospective study of patients with skin cancer. J Cutan Med Surg. 2002:6:427-9.

15. English DR, Kricker A, Heenan PJ, Randell PL, Winter MG, Armstrong BK. Incidence of nonmelanocytic skin cancer in Geraldton, Western Australia. Int J Cancer. 1997;73:629-33.

16. Cherpelis BS, Marcusen C, Lang PG. Prognostic factors for metastasis in squamous cell carcinoma of the skin. Dermatol Surg. 2002;28:268-73.

17. Košec A, Svetina L, Lukšić I. Significance of clinical stage, extent of surgery and outcome in cutaneous squamous cell carcinoma of the head and neck. Int J Oral Maxillofac Surg. 2013;42:82-8

18. Afzelius LE, Gunnarsson M, Nordgren $H$. Guidelines for prophylactic radical lymph node dissection in cases of carcinoma of the external ear. Head Neck Surg. 1980;2:361-5.

19. Lee D, Nash M, Har-El G. Regional spread of auricular and periauricular cutaneous malignancies. Laryngoscope. 1996;106:998-1001.

20. Lai SY, Weinstein GS, Chalian AA, Rosenthal DI, Weber RS. Parotidectomy in the treatment of aggressive cutaneous malignancies. Arch Otolaryngol Head Neck Surg. 2002;128:521-6.

21. Rowe DE, Carroll RJ, Day CL, Jr. Prognostic factors for local recurrence, metastasis, and survival rates in squamous cell carcinoma of the skin, ear, and lip. Implications for treatment modality selection. J Am Acad Dermatol. 1992;26:976-90.

22. Huang CC, Boyce SM. Surgical margins of excision for basal cell carcinoma and squamous cell carcinoma. Semin Cutan Med Surg. 2004;23:167-73.

23. Peat $B$, Insull $P$, Ayers R. Risk stratification for metastasis from cutaneous squamous cell carcinoma of the head and neck. ANZ J Surg. 2012;82:230-3.

24. Solares CA, Lee K, Parmar P, O'Rourke P, Panizza B. Epidemiology of clinical perineural invasion in cutaneous squamous cell carcinoma of the head and neck. Otolaryngol Head Neck Surg. 2012;146:746-51.

25. Frierson HF Jr, Cooper PH. Prognostic factors in squamous cell carcinoma of the lower lip. Hum Pathol. 1986;17:346-54.

26. de Visscher JG, Gooris PJ, Vermey A, Roodenburg JL. Surgical margins for resection of squamous cell carcinoma of the lower lip. Int J Oral Maxillofac Surg. 2002;31:154-7.

27. Brodland DG, Zitelli JA. Surgical margins for excision of primary cutaneous squamous cell carcinoma. J Am Acad Dermatol. 1992;27:241-8.

28. Veness MJ. High-risk cutaneous squamous cell carcinoma of the head and neck. J Biomed Biotechnol. 2007;2007:80572.

29. Czarnecki D, Staples M, Mar A, Giles G, Meehan C. Metastases from squamous cell carcinoma of the skin in southern Australia. Dermatology. 1994;189:52-4.

30. Gurudutt VV, Genden EM. Cutaneous squamous cell carcinoma of the head and neck. J Skin Cancer. 2011:2011:502723.
31. Motley R, Kersey P, Lawrence C; British Association of Dermatologists; British Association of Plastic Surgeons; Royal College of Radiologists, Faculty of Clinical Oncology. Multiprofessional guidelines for the management of the patient with primary cutaneous squamous cell carcinoma. Br J Dermatol. 2002;146:18-25.

32. Schmitt JV, Miot HA. Actinic keratosis: a clinical and epidemiological revision. An Bras Dermatol. 2012;87:425-34.

33. Ocanha JP, Dias JT, Miot HA, Stolf HO, Marques ME, Abbade LP. Relapses and recurrences of basal cell face carcinomas. An Bras Dermatol. 2011;86:386-8.

34. Kyrgidis A, Tzellos TG, Kechagias N, Patrikidou A, Xirou P, Kitikidou K, et al. Cutaneous squamous cell carcinoma (SCC) of the head and neck: risk factors of overall and recurrence-free survival. Eur J Cancer. 2010;46:1563-72.
MAILING ADDRESS:

Luciana Patricia Fernandes Abbade

Departamento de Dermatologia e Radioterapia da FMB-

Unesp, Campus Universitário de Rubião Jr.

18.618-970 - Botucatu - SP

Brazil

E-mail: lfabbade@fmb.unesp.br

How to cite this article: Vasconcelos L, Melo JC, Miot HA, Marques MEA, Abbade LPF. Invasive head and neck cutaneous squamous cell carcinoma: clinical and histopathological characteristics, frequency of local recurrence and metastasis. An Bras Dermatol. 2014;89(4):562-8. 